\title{
Childhood Overweight and Obesity - Beyond Television Viewing
}

\author{
Tanuj Kanchan
}

$\mathrm{C}$ Thildhood overweight and obesity is attaining alarming proportions globally. Decreasing physical activity is considered as one of the well-established and preventable causes for the increasing incidence of childhood overweight and obesity. Thus, the need of the hour is to recognize and resolve the various causes associated with the lack of physical activities. In this regard, the correspondence by Kapil and Bhadoria ${ }^{[1]}$ is very apt as it highlights the association between television viewing and overweight and obesity among children.

Though studies worldwide have confirmed this association, there apparently has been a shift in childhood interests lately. With modernization and technological advancement, more and more children are now glued to their mobiles, tablets, iPads, gaming consoles, laptops, etc., It is not an uncommon sight to see very young kids spending a lot of time on these gadgets, especially in the urban areas. Excessive use of these gadgets obviously can be linked to decrease in the average number of hours spent in television viewing. Thus, it needs to be highlighted that the association between duration of television viewing alone and childhood overweight and obesity should be read with caution. It is advisable that all the aforementioned causes that keep the kids away from physical activities be considered together by the researchers while studying their effect on childhood overweight and obesity.

The causes for childhood overweight and obesity may vary in different setups and, hence, more studies should be taken up in different setups to understand the problem status, so that appropriate preventive measures are planned and taken up accordingly. Increased physical activity, however, remains the mainstay in the prevention of childhood overweight and obesity.

\section{REFERENCES}

1. Kapil U, Bhadoria AS. Television viewing and overweight and obesity amongst children. Biomed J 2014;37:337-8.

From the Department of Forensic Medicine, Kasturba Medical College, Mangalore, India

Received: Nov. 11, 2014; Accepted: Jan. 13, 2015

Correspondence to: Dr. Tanuj Kanchan, Department of Forensic Medicine and Toxicology, Kasturba Medical College, Mangalore, Manipal University, India. State Highway 65, Madhav Nagar, Manipal, India. Tel.: 91-9448252394; Fax: 91-824-2428183; E-mail: tanuj.kanchan@ manipal.edu

DOI: $10.4103 / 2319-4170.151184$ 